\title{
Fuzzy logic based risk assessment system giving individualized advice for metabolic syndrome and fatal cardiovascular diseases
}

\author{
Hayriye Korkmaz ${ }^{\mathrm{a}}$, Emre Canayaz ${ }^{\mathrm{b}, *}$, Sibel Birtane Akar $^{\mathrm{c}}$ and Zehra Aysun Altikardes ${ }^{\mathrm{d}}$ \\ ${ }^{a}$ Department of Electric and Electronics Engineering, Faculty of Technology, Marmara University, \\ Istanbul, Turkey \\ ${ }^{\mathrm{b}}$ Department of Electric and Electronics Engineering, Institute of Pure and Applied Sciences, Marmara \\ University, Istanbul, Turkey \\ ${ }^{\mathrm{c}}$ Department of Computer Programming, Vocational School, Istanbul Arel University, Istanbul, Turkey \\ ${ }^{\mathrm{d}}$ Department of Computer Technologies, Vocational School of Technical Sciences, Marmara \\ University, Istanbul, Turkey
}

\begin{abstract}
In 2005, global cardiovascular diseases caused 30\% of deaths in Europe, which is $46 \%$ of total deaths for all death groups. Today, according to the International Adult Diabetes Federation, 20\% to 25\% of the adult population in the world has Metabolic Syndrome. Turkish Statistical Institute claims that in Turkey 408782 people died of circulatory system diseases in 2016 and it is expected that numbers will dramatically increase. In 2003, total worldwide healthcare budget of Diabetes Mellitus was up to 64.9 billion International Dollars with the continuing rise in prevalence, it is expected that total costs will increase to 396 billion International Dollars by 2025.

The main purpose of this study was to present a clinical decision support system that calculates Metabolic Syndrome existence and evaluate HeartScore risk level for Turkish population. The second objective was to create a detailed personal report about individual's risk level of Metabolic Syndrome and HeartScore and give advice to him/her to reduce it. The fuzzy logic risk assessment system (FLRAS) was formed in LabVIEW graphical development platform according to International Diabetes Federation and European Heart Journal's criteria. Mamdani type fuzzy logic sets were identified for each input variable and membership functions were assigned depending on the magnitude of the input limits. System's performance was tested on 96 (72 females, 24 males) patient data. Results show that the proposed system was able to evaluate the Metabolic Syndrome risk with 0.9285 specificity, 0.92708 accuracy and 0.925 sensitivity.
\end{abstract}

Keywords: Fuzzy logic, decision support system, automatic report generation, individualized medical advices

\section{Introduction}

The main reason for $46 \%$ deaths in Europe, $30 \%$ for deaths globally was Cardiovascular diseases (CDV) in 2015 [1]. Turkish Statistical Institute claims that in Turkey 408782 people died of circulatory system diseases in 2016 and it is expected that numbers will dramatically increase [2]. Metabolic Syndrome (MetS) is a combination of biochemical and physiological abnormalities associated with CVD

\footnotetext{
${ }^{*}$ Corresponding author: Emre Canayaz, Marmara University, Göztepe, 34722, Istanbul, Turkey. E-mail: emre.canayaz@ marmara.edu.tr.
}

0928-7329/19/\$35.00 (c) 2019 - IOS Press and the authors. All rights reserved

This article is published online with Open Access and distributed under the terms of the Creative Commons Attribution NonCommercial License (CC BY-NC 4.0). 
Table 1

IDF 2005 metabolic syndrome criteria [12]

\begin{tabular}{|c|c|c|c|c|c|c|}
\hline & WCM & LDL & HDL & SBP & DBP & FPG \\
\hline $\begin{array}{l}\text { Female } \\
\text { Male }\end{array}$ & $\begin{array}{l}\geqslant 80 \mathrm{~cm} \\
\geqslant 94 \mathrm{~cm}\end{array}$ & $\geqslant 150 \mathrm{mg} / \mathrm{dl}$ & $\begin{array}{l}<50 \mathrm{mg} / \mathrm{dl} \\
<40 \mathrm{mg} / \mathrm{dl}\end{array}$ & $\geqslant 130 \mathrm{mmHg}$ & $\geqslant 85 \mathrm{mmHg}$ & $\geqslant 100 \mathrm{mg} / \mathrm{dl}$ \\
\hline
\end{tabular}

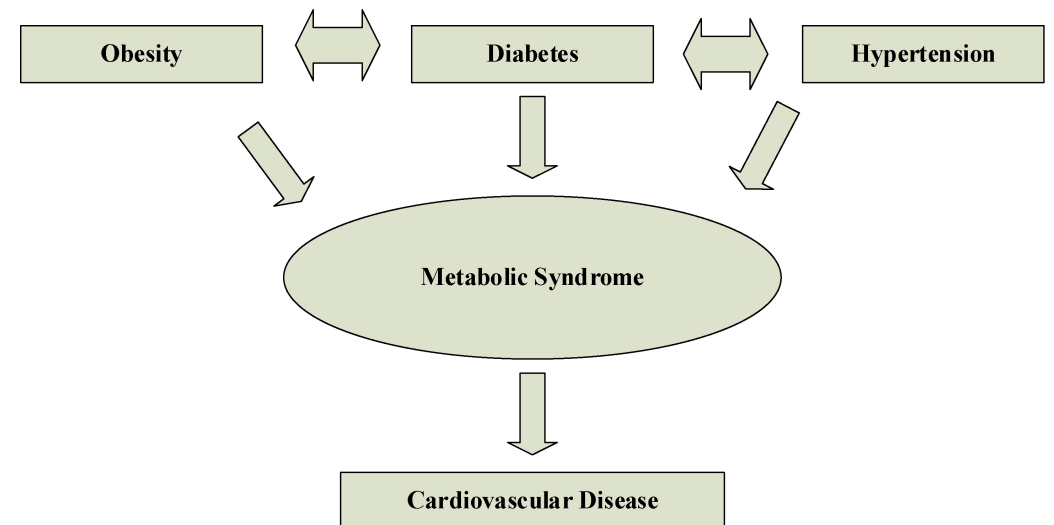

Fig. 1. General structure of the relationship between MetS risk factors and CVD.

and Type 2 DM (T2DM) development. As represented in Fig. 1, there is a strong relationship between main risk factors of MetS and CVD. Another important risk factor is central obesity that increases the risk of diagnosed as T2DM. Hence, as T2DM risk increases, MetS risk and CVD risks are increasing, too. Therefore, early detection of MetS is important to prevent and reduce cardiovascular risks. This will reduce the cost of health care for DM and related diseases and also reduce the risk levels of people worldwide [3].

Today, over 300 million people worldwide suffer from Diabetes Mellitus (DM), and according to the International Adult Diabetes Federation, $20 \%$ to $25 \%$ of the adult population in the world has MetS [4,5]. By 2010 , it was estimated that $31 \%$ of the male population and $43 \%$ of the female population in Turkey suffers from metabolic syndrome [6]. Hence approximately 9.2 million adults, including 5.3 million women, have metabolic syndrome in Turkey [6].

So, with this study, it was aimed to propose a Clinical Decision Support System (CDSS) that evaluates MetS existence and calculates the risk level according to the Heart Score chart. The HeartScore chart is a data set containing information, which enables to calculate fatal cardiovascular risk level [7,8]. Our system is based on Turkish HeartScore risk chart [9].

The second purpose is to create a detailed report about MetS and HeartScore risks and to give some individualized advice to him/her to reduce them by focusing on high-risk indicators. For this; the FLRAS was formed in LabVIEW graphical development platform according to IDF's and European Heart Journal's criteria. Mamdani type fuzzy logic sets were identified for each input variable and membership functions were assigned depending on the magnitude of the input limits.

According to the IDF standards that we used in our study; abdominal obesity is a prerequisite for setting MetS diagnosis for a person [5]. That is, the waist circumference measurement (WCM) and the other two factor values exceeding the stated ethnicity of the individual should be higher than the normal limits as demonstrated in Table $1[5,10,11]$. Those four factors can be listed as follows: increased triglycerides (LDL), reduced HDL-c, raised systolic blood pressure (SBP) or raised diastolic blood pressure 


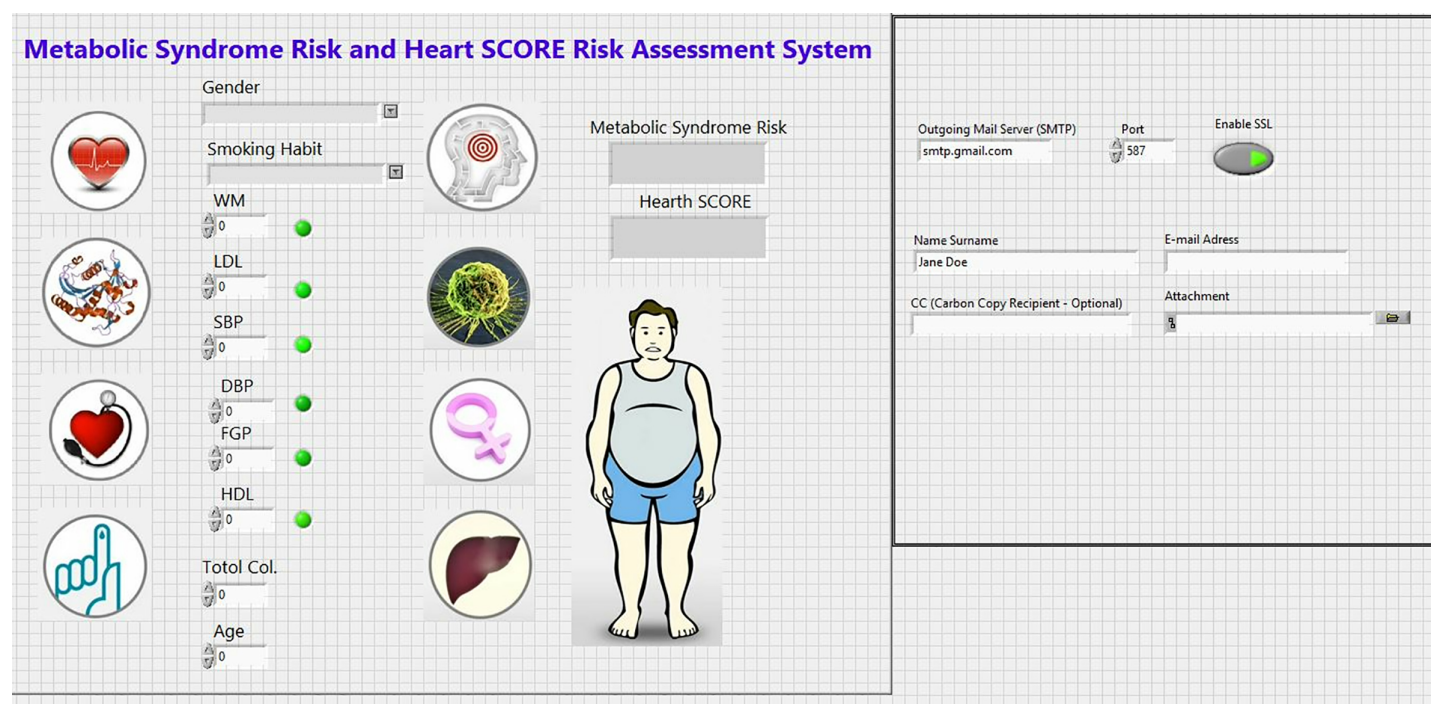

Fig. 2. Front panel of the proposed FLRAS.

(DBP) and raised fasting plasma glucose (FPG). Although LDL, SBP, DBP and FGB were applicable to both genders with same limit values, WCM and HDL differ [11].

The rest of this paper is organized as follows: Similar studies in the literature were given in Section 2. In Section 3, detailed information about the proposed system and its general structure was given. In addition, generation of fuzzy rules were explained, too. In Section 4, tests results were given and the proposed MetS risk assessments system was evaluated by giving Specificity, Accuracy and Sensitivity parameters. In the last section, results' consistency was discussed. In addition, a few limitations of the system were given. Next, future works planned for solutions of these problems were explained.

\section{Related works}

In the literature, there are many medical decision support systems developed in a similar way of artificial intelligence algorithms. According to Kong et al. [13], CDSS can give a more accurate diagnosis and treatment guidelines using artificial intelligence and soft computing techniques as fuzzy logic system (FLS) Ivanović et al. [14] did. They claimed that ANNS is a suitable soft computing technique for detecting MetS risks [14]. Malmir et al. [15] presented a CDSS modeled by FLS that collects set of significant symptoms for a kidney stone and a kidney infection diagnosis. Also, Nazari et al. [16] tried to develop an expert system using fuzzy analytic hierarchy process for diagnosis of CVD and used changeable risk factors (Obesity, air pollution, stress lack of exercise, eating habit, smoking behavior, mental factors), controllable risk factors (HDL-c, LDL, DBP, kidney problems, diabetes) and unchangeable risk factors (age, gender, inheritance, genetic factors, unknown factors) as input to calculate CVD risk. Moreover, with advancements in medical image processing Soltani et al. [17] created a FLS that detect early glaucoma diagnosis. Also, another FSL study focused on breast cancer classification using expectation maximization to cluster same the data in similar groups and classification and regression trees method to create the fuzzy rule that combines input data and the output clustering result [18]. In a search on Google Scholar with keywords "Turkey", "HeartScore", "Metabolic Syndrome", and "Fuzzy Logic Risk Assessment", it has been determined that there is no similar system to the proposed FLRAS. 
Table 2

Recommendation examples to decrease the risk level caused by WCM, LDL and HDL

\begin{abstract}
WCM One of the most critical elements of the Metabolic Syndrome Risk Test is the weight. Your waist circumference is above the limits. Therefore, you need to take precautions to provide weight control. For this, you should see your physician, exercise regularly and diet under the supervision of a specialist.

HDL Your HDL level is below normal limits. The most important mechanism for raising high-density lipoprotein is exercise. In addition, if you smoke, you should quit or reduce smoking. It will help your HDL level rise.
\end{abstract}
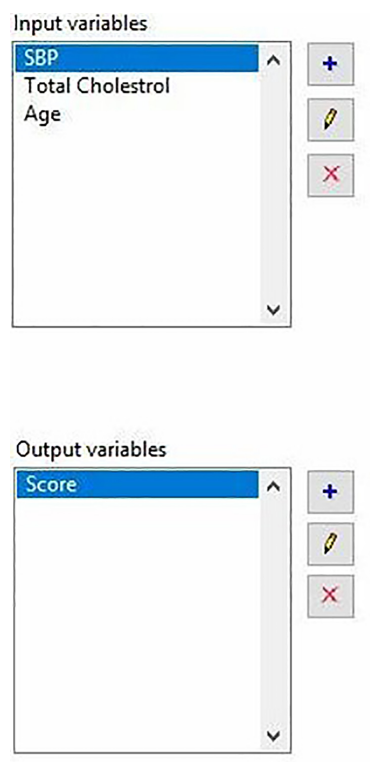
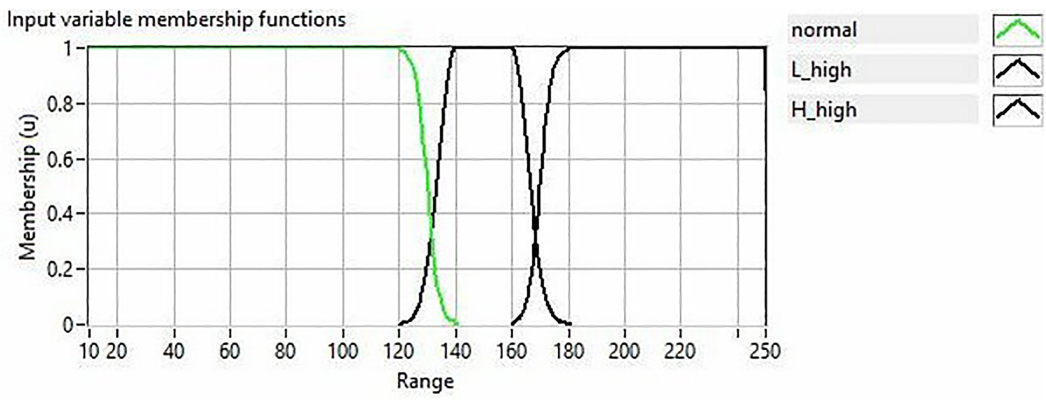

(a)
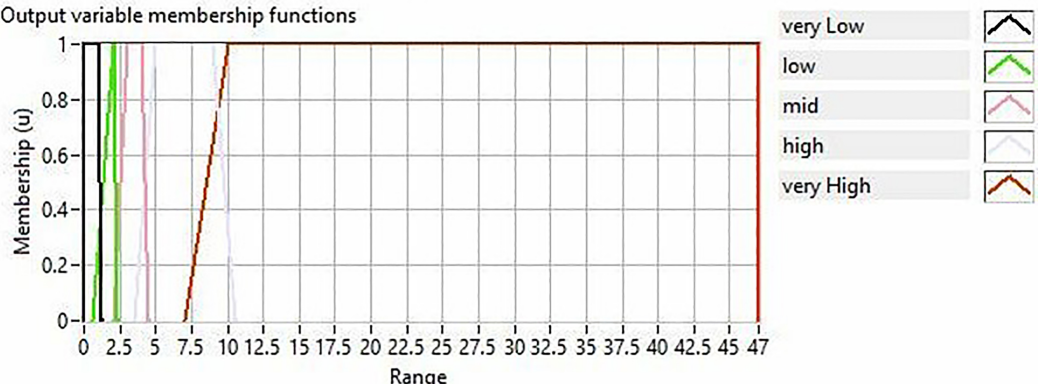

(b)

Fig. 3. An example for input membership functions. (a) WCM variables. (b) WCM variable for female.

\title{
3. Proposed fuzzy logic based risk assessment system
}

The proposed system consists of two main parts: one of them is the front panel and the other one is block diagram. Input variables such as WCM, LDL, HDL, SBP, DBP, FGP, total cholesterol level, smoking habits, gender and subject e-mail addresses were entered into the system via the front panel shown in Fig. 2.

The second part of suggested CDSS is the block diagram where all the tasks were conducted including as follows: fuzzification/defuzzification processes for risk analysis of MetS and HeartScore, rule creation, individualized report generation and e-mailing process. All of the crisp numeric data was transformed into the fuzzy form using different membership functions for each of male and female test subjects as seen in Fig. 3a and b. Upper and lower limits of these variables were formed according to IDF criteria for MetS risk and European Heart Journal criteria for Heart Score risk calculation. Beside, all membership functions were calibrated based on Turkey's Endocrinology Metabolism Association guidelines for Turkish population [19].

Output membership functions for HeartScore risk level are given in Fig. 4. In our system, centroid defuzzification method was used due to its simplicity and the widespread usage in different applications. Twenty-one linguistic rules for Mets analysis and 43 linguistic rules for HeartScore were defined for 
Table 3

Confusion matrix for MetS risk assessment

\begin{tabular}{lllcc}
\hline & & \multicolumn{2}{c}{ Predicted } \\
\cline { 3 - 5 } & & & Negative & Positive \\
\hline ACTUAL & METS & Negative & 37 & 4 \\
& FEMALE & Positive & 3 & 28 \\
& METS & Negative & 15 & 0 \\
MALE & Positive & 0 & 9 \\
\hline
\end{tabular}

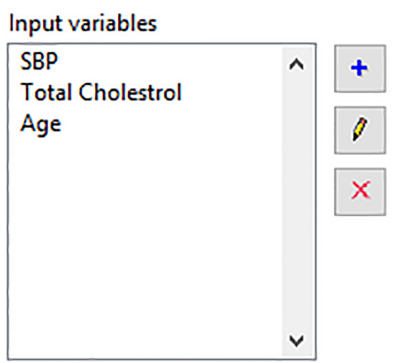

Input variable membership functions

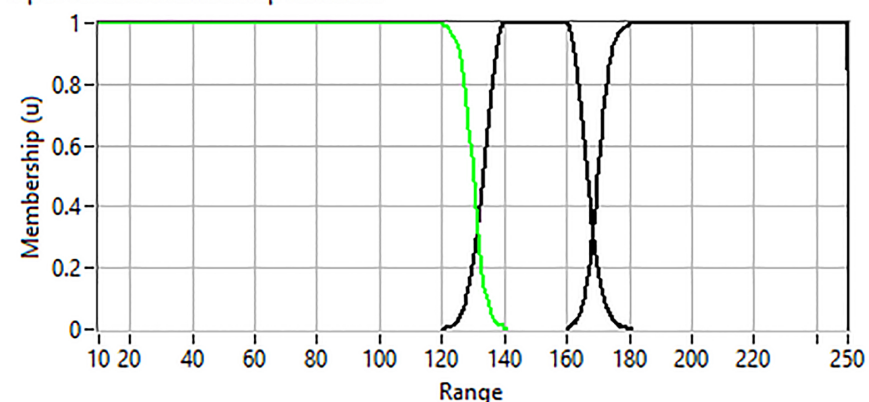

(a)

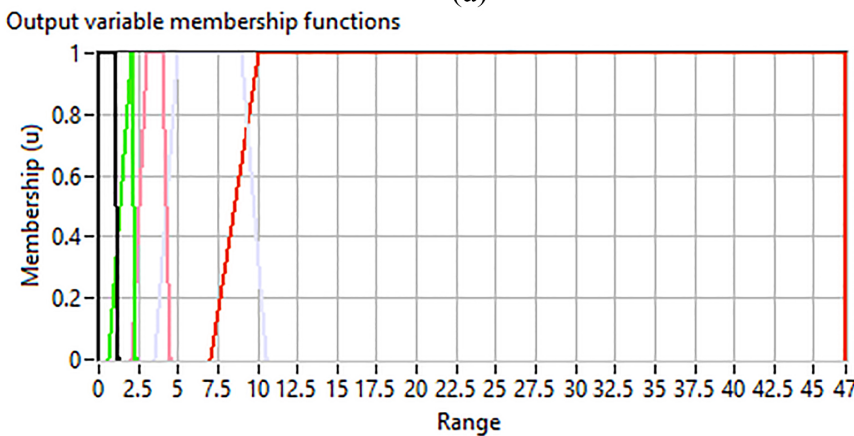

(b) normal

L_high

H_high
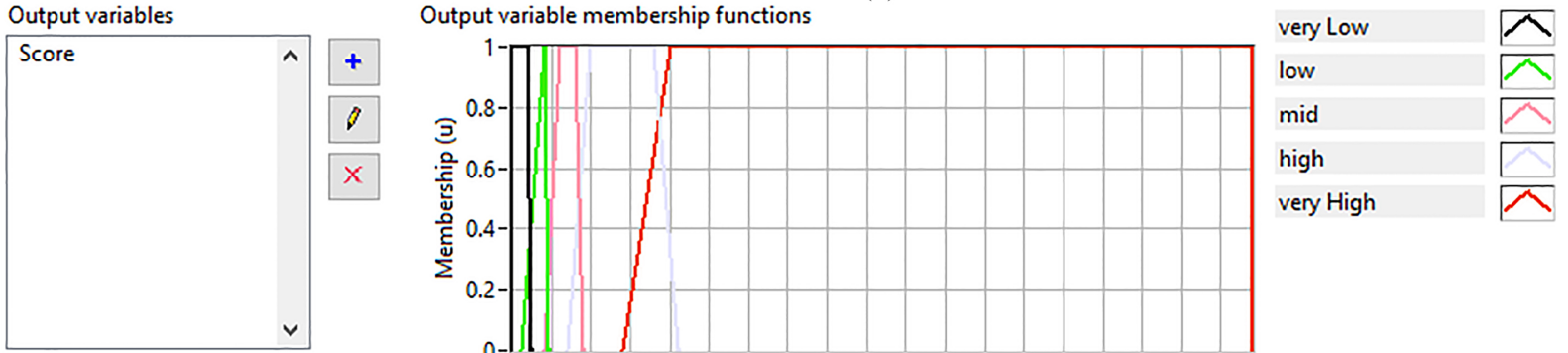

Fig. 4. Output membership function examples for MetS risk evaluation. (a) For male. (b) For female.

men and women, respectively. A small part of the rules are presented in Fig. 5. The next step was to create a report indicating the risk levels of the person including suggestions in order to reduce the MetS risk level and the HeartScore (Table 2). In total, 12 suggestions were created and two of them can be seen in Table 2 as an example. LabVIEW MSOffice Report subVI was used to create the reports in .doc format. Recommendations were formed by using IDF's conclusions on the definition of the metabolic syndrome [4] and the work of Conroy et al. [7]. The final step of the system was designed to send an e-mail with an attachment including a report that created automatically.

\section{Results}

System's performance was tested on 96 (72 females, 24 males) patient data and results from the proposed system were compared with the real medical decision made from IDF's criteria and HeartScore risk table. Data were obtained from Marmara University's Hypertension and Arteriosclerosis Research 
Table 4

MetS risk assessment performance of the proposed system

\begin{tabular}{llll}
\hline Gender & Specificity & Accuracy & Sensitivity \\
\hline Male & 1 & 1 & 1 \\
Female & 0.902439 & 0.902778 & 0.903226 \\
Both & 0.928571429 & 0.927083 & 0.925 \\
\hline
\end{tabular}

Table 5

HeartScore risk assessment performance of the proposed system

\begin{tabular}{lccc}
\hline & Specificity & Accuracy & Sensitivity \\
\hline Non smoking & 0.9565 & 0.9761 & 1 \\
Smoking & 0.9090 & 0.9756 & 1 \\
\hline
\end{tabular}

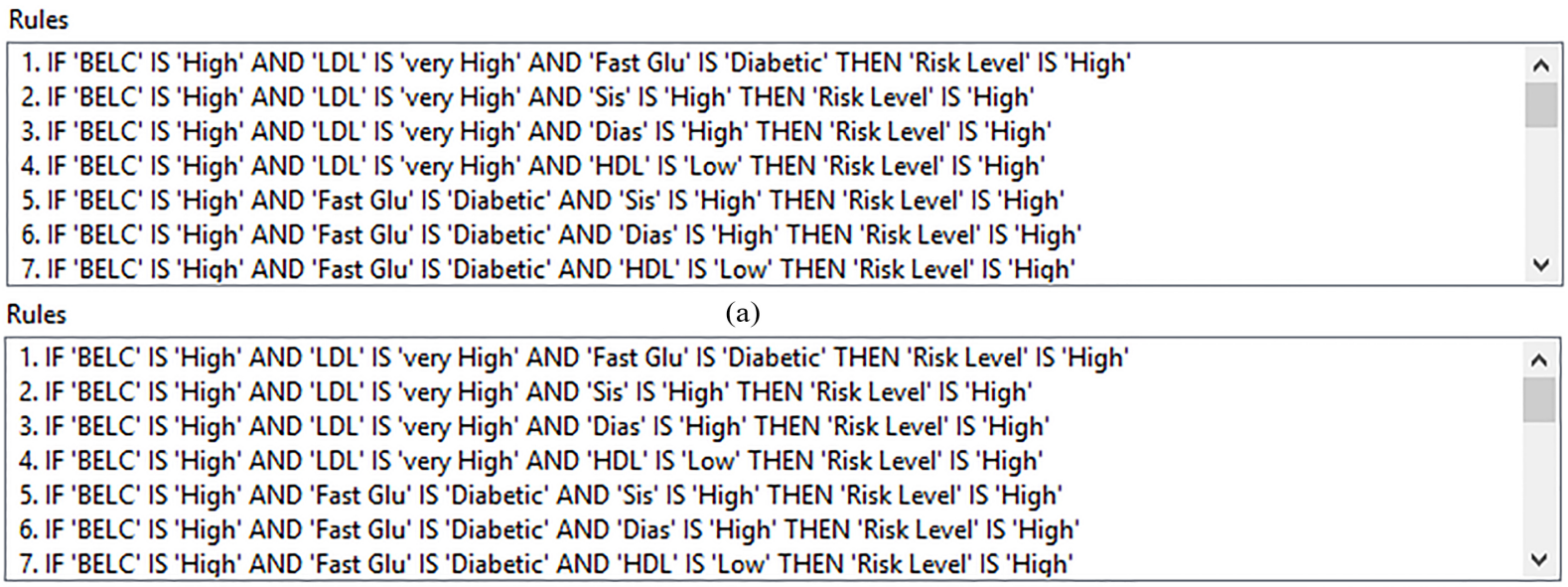

(b)

Fig. 5. Linguistic rule samples. (a) For MetS risk evaluation. (b) For HeartScore calculation.

and Implementation Centre. All patient data were contained WM, LDL, HDL, SBP, DBP, FGP, total cholesterol level, smoking habit and gender. MetS risk assessment decision matrix was presented in Table 3 .

The proposed FLRAS works with 0.9025 specificity, 0.9028 accuracy and 0.9032 sensitivity for females' data and 1 specificity, 1 accuracy and 1 sensitivity for males' data. Over all for both genders, system's performance scores for MetS risk analysis were 0.9285 for specificity, 0.92708 for accuracy and 0.925 for sensitivity (Table 4 ).

Obtained data were lack of information about smoking habits of the individual. Thus to test the performance of proposed system's assessment ability to calculate HeartScore, whole data's age, SBP and total cholesterol values were entered to system through from front panel of FLS. Results were compared with the European Guidelines on CVD Prevention's HeartScore chart to obtain decision matrix, which represents the system's ability to deal with uncertainty and classification abilities. Results for assessment of fatal cardiac risk for ten years represented in Table 5. Moreover, when we performed the two-tailed paired t-test, a statistically significant difference between HeartScore results between smoking and non-smoking habits of the same individual was observed $(p<0.00035896)$. Hereby, system evaluated different scores for smoking and nonsmoking conditions of test subjects. 


\section{Discussion}

The proposed FLRAS calculated individual's MetS risk based on IDF's criteria [4] and fatal cardiovascular risk based on HeartScore [7] for Turkish population and generated a report containing risk analysis and advice to reduce risk level and e-mail it. The greatest novelty of this study is that there is no other fuzzy based system for the calculation of HeartScore and MetS risk assessment that targeting the Turkish population. The proposed FLRAS have a user-friendly interface enabled calculating outputs by simply entering input variables. Besides, proposed advices not only planned to reduce CVD risk; but also MetS risk level, too. Our results were consistent with practical clinically used standards defined by IDF and European Society of Cardiology. Moreover, high or low risk limits of input and output variables can be altered according to related country's CVD risk classification $[1,8,20]$. Consequently, proposed system was suitably designed to add new input and output variables, to change their membership functions or to update the limits according to up-to-date developments.

One major drawback of proposed CDSS is the focusing on a specific age group varying between 40 and 65 for Heart Score system [3]. Moreover, input and output values can be altered according to high risk or low-risk level of related country's CVD risk classification $[1,8,20]$. Consequently, proposed system was designed to adapt to latest updates by changing defined membership function limit values or adding new membership inputs or outputs according to the up-to-date developments.

Another important limitation was the missing information about smoking habits of subjects that we used to test our system. Although t-test proves that system calculates statistically different risk results for smoking and non-smoking habits, the next system should be tested with a complete dataset including smoking habit of individuals. Since MetS is strongly associated with T2DM, future studies may focus on the calculated risk values of T2DM patients and develop a clinical decision support system that calculates T2DM disease risk levels.

\section{Conflict of interest}

None to report.

\section{References}

[1] WHO, Prevention of Cardiovascular Disease: Guidelines for Assessment and Management of Cardiovascular Risk. 2007, World Health Organization: Geneva, Switzerland.

[2] Institute TS. Ölüm Nedeni İstatistikleri, 2016. 2017 [cited 2018 27.04]; Available from: http://www.tuik.gov.tr/PreHaber Bultenleri.do?id=24572.

[3] Mortensen MB, Falk E. Limitations of the SCORE-guided European guidelines on cardiovascular disease prevention, European Heart Journal. 2017; 38(29): 2259-2263.

[4] George Alberti PZ, Jonathan S, Scott Grundy. The IDF Consensus Worldwide Definition of the Metabolic Syndrome, 2006, International Diabetes Federation: Brussels, Belgium.

[5] Nam Han C (chair), Jean Claude Mbanya JK, Katherine O, Leonor G, Wolfgang R, Gojka R, Nita F, Rana D, Alireza E, Edward B, Ian H, Otaliba Libânio de MN, Pablo AM, Hashank J, Juliana C, Jonathan S, Thelma AS, Meda P, Ahmed R. IDF DIABETES ATLAS - 8TH EDITION, J.d.R.F. Suvi Karuranga, Yadi Huang, Belma Malanda, Editor. 2017, International Diabetes Federation: Brussels, Belgium.

[6] Derne TK. Koroner Kalp Hastalı̆̆ Korunma Ve Tedavi Kılavuzu http://www.tkd.org.tr/kilavuz/k11.htm.eriflimtarihi.27. 04.2018. J PMR Sci. 2010; 13 Suppl: 4-9 Nesrin Demirsoy Kardiyovasküler Hastalıkların Epidemiyolojisi 2010.

[7] Conroy RM, et al., Estimation of ten-year risk of fatal cardiovascular disease in Europe: the SCORE project, European Heart Journal. 2003; 24(11): 987-1003. 
[8] Cardiology E.A.o.P. HeartScore, Ascess HeartScore Online. 2018 [cited 2018 31.01]; Available from: http://www.heart score. org/en_GB/access.

[9] Association TC. HeartScore Turkey. 2018 [cited 201804 May 2018]; Available from: http://www.heartscore.org/tr_ TR/access-heartscore.

[10] Sattar N, et al., Metabolic syndrome with and without c-reactive protein as a predictor of coronary heart disease and diabetes in the west of scotland coronary prevention study, Circulation. 2003; 108(4): 414-419.

[11] Einhorn D, et al., American College of Endocrinology position statement on the insulin resistance syndrome. Endocrine practice: official journal of the American College of Endocrinology and the American Association of Clinical Endocrinologists. 2003; 9(3): 237-252.

[12] Birtane S, et al., Development of decision support system using Mamdani type fuzzy logic clusters for metabolic syndrome risk assesment. in 2017 Medical Technologies National Congress (TIPTEKNO), 2017.

[13] Kong G, Xu D-L, Yang J-B, Clinical Decision Support Systems: A Review on Knowledge Representation and Inference Under Uncertainties, International Journal of Computational Intelligence Systems. 2008; 1(2): 159-167.

[14] Ivanović D, et al., ANN Prediction of Metabolic Syndrome: a Complex Puzzle that will be Completed, Journal of Medical Systems. 2016; 40(12): 264.

[15] Malmir B, Amini M, Chang SI. A medical decision support system for disease diagnosis under uncertainty, Expert Syst Appl. 2017; 88: 95-108.

[16] Nazari S, et al., A fuzzy inference- fuzzy analytic hierarchy process-based clinical decision support system for diagnosis of heart diseases, Expert Systems with Applications. 2018; 95: 261-271.

[17] Soltani A, et al., A new expert system based on fuzzy logic and image processing algorithms for early glaucoma diagnosis, Biomedical Signal Processing and Control. 2018; 40: 366-377.

[18] Nilashi M, et al., A knowledge-based system for breast cancer classification using fuzzy logic method, Telematics and Informatics. 2017; 34(4): 133-144.

[19] Derneği T.E.v.M, Lipid metabolizma bozukluklari tani ve tedavi kilavuzu, T.E.v.M. Derneği, Editor, 2017

[20] Piepoli MF, et al., 2016 European Guidelines on cardiovascular disease prevention in clinical practiceThe Sixth Joint Task Force of the European Society of Cardiology and Other Societies on Cardiovascular Disease Prevention in Clinical Practice (constituted by representatives of 10 societies and by invited experts) Developed with the special contribution of the European Association for Cardiovascular Prevention \& Rehabilitation (EACPR), European Heart Journal. 2016; 37(29): 2315-2381. 